\title{
Recurrent Malignant Neoplasm of Salivary Gland
}

National Cancer Institute

\section{Source}

National Cancer Institute. Recurrent Malignant Neoplasm of Salivary Gland. NCI

Thesaurus. Code C35675.

The reemergence of a malignant salivary gland neoplasm after a period of remission. 